\title{
Interplay of gender on emotional maturity and relationship of emotional maturity with the adjustment of adolescents residing in orphanages, single parent families and intact families
}

\author{
Rashmi Upreti and Seema Sharma
}

Received: 04.04.2018; Revised: 11.10.2018; Accepted: 24.10.2018

See end of the paper for authors' affiliations Rashmi Upreti Department of Human Development and Family Studies, Punjab Agricultural University, Ludhiana (Punjab) India Email : rashmi.upreti696@ gmail.com
ABSTRACT : The present investigation aimed at assessing and comparing the emotional maturity of adolescents from orphanages, single parent families and intact families across gender. Also, the relationship between emotional maturity and adjustment was explored. A sample of 100 adolescents from orphanages and 200 adolescents from government schools (100 from single parent families and 100 from intact families) has been selected through random sampling technique. Emotional Maturity Scale and Bell's Adjustment Inventory were administered in the present study. Analysis of data revealed that girls belonged to intact families were significantly more emotionally progressed and socially adjusted. In overall emotional maturity also, girls were more emotionally mature when compared with boys. Also, the total emotional maturity of boys from orphanages and intact families was found to be positively correlated with their adjustment. Whereas, adolescents living with single parent families reported negative correlation. Interestingly, the independency of all the adolescent boys irrespective of their family type was found to be negatively correlated with their adjustment. Overall emotional maturity of girls belonging to orphanages was significantly and positively correlated with the adjustment. Furthermore, integrated personality of girls from orphanages and independence of girls belonging to single parent families also found significantly and positively correlated with the adjustment.

KEY WORDS: Emotional stability, Intact families, Orphans, Single parent families, Social adjustment

HOW TO CITE THIS PAPER : Upreti Rashmi and Sharma, Seema (2018). Interplay of gender on emotional maturity and relationship of emotional maturity with the adjustment of adolescents residing in orphanages, single parent families and intact families. Asian J. Home Sci., 13 (2) : 502-508, DOI: 10.15740/ HAS/AJHS/13.2/502-508. Copyright@ 2018: Hind Agri-Horticultural Society. 